\title{
A Comparison of Active and Passive Virtual Reality Exposure Scenarios to Elicit Social Anxiety
}

Yoones A. Sekhavat, Poorya Nomani

Faculty of Multimedia, Tabriz Islamic Art University, Iran

\{Sekhavat,p.Nomani\}@tabriziau.ac.ir

Abstract

Social phobia is an anxiety disorder that results in an excessive and unreasonable fear of social situations. As a safe and controlled tool, Virtual Reality Exposure Therapy (VRET) has been used to treat anxiety disorders and phobias. This paper aims to study whether VRET with active scenarios can challenge a person more than passive scenarios. By comparing participants who were exposed to active and passive scenarios in VRET, we show that active scenarios are more effective than passive scenarios to elicit social anxiety in healthy participants. We focus on eliciting social anxiety and creating the sense of presence as two parameters enhancing the efficacy of VRET scenarios.

Keywords: Virtual Reality Exposure, Serious Games, Social Phobia, Cognitive Behavior;

\section{Introduction}

Social phobia is a common anxiety disorder that affects considerable population of the world [1]. Depression, restricted socialization, deficit in social skill, poor education and employment performance are among common effects of this disorder. In some cases, people suffering from social phobia have a strong fear of being judged by others that results in avoiding to attend in social situations such as walking on streets, talking to people, communications with sellers, using public restrooms, and speaking in a class or a meeting. Research has already shown the effectiveness of cognitive behavioral therapy (CBT) [2-7] to treat this anxiety disorder. The goal of CBT is to train people to cope with social phobia [8]. CBT includes a set of interventions in order to make changes in the content and context of behaviors, thoughts, and feelings [9].

Exposure therapy, which involves the exposure of a patient to the feared object or context, is an effective treatment for social anxiety disorders [10]. In recent years, virtual reality and simulated environments have gained popularity in the treatment of various mental and physical disorders [11 -18]. A significant proportion of individuals with social anxiety disorder prefer virtual reality exposure therapy (VRET) to in vivo exposure. In comparison to in vivo exposure, VRET has advantages of the full control over the severity of scenarios, lower costs, and the possibility of holding therapy sessions in a safe environment. According to the emotional processing theory [19], the virtual environment in VRET should be generalizable to real-life situations in order to provide the sense of immersion. Such an environment can elicit physiological arousal addressing the core elements of the fear. Fulfilling these requirements is closely related to a "fear-eliciting" environment.

With the advent of virtual reality as a clinical tool, it will grow increasingly important to identify factors that might mitigate or enhance the effectiveness of these technologies. As one of these important factors, we argue in comparison to passive VRET scenarios, active scenarios that dynamically require actions and decisions during the exposure scenarios can result in a better "fear-eliciting" environment. Previous research shows that virtual reality can elicit physiological arousal as well as self-reported distress [20]. However, no research has compared the effects of active and passive VRET scenarios for this purpose. This study extends previous research in three ways. First, we examine and compare the ability of active and passive exposure scenarios in terms of eliciting subjective distress. We hypothesize that when placed in either a passive or an active virtual social interaction situation, healthy people would experience subjective distress. We also hypothesize that individuals would have a greater increase in subjective distress in the case of active scenarios than passive VRET scenarios. Second, we hypothesize that all participants would feel present during both active and passive scenarios, but more so during active exposure 
scenarios. Finally, we hypothesize that participants would feel more entertained using active scenarios than passive scenarios.

\section{Motivation: Active vs. Passive VRET Scenarios}

The motivation behind our hypothesis that the active exposure scenarios should be superior to passive scenarios comes from the rapidly developing literature on human-computer-interaction and virtual reality. Virtual reality is a $3 \mathrm{D}$ computer generated environment that is explored and interacted with [21, 22]. In this setting, the person feels immersed in the virtual world such that she becomes a part of this world. Generally, virtual reality applications employ head mounted displays (HMDs) to present a virtual environment. This setting results in the sense of being "in" the virtual environment than just observing it from the outside. This psychological sense is called "presence" [23-24] in the human computer interaction literature. Lawful and meaningful responses to an individual in a VR environment results in the sense of presence [24, 25]. Thus, interactive scenarios in which the content of the VR environment is changed in real-time in response to the behavior of users are more likely to elicit presence. We argue such active scenarios result in more presence, that consequently increase the quality of exposure. Despite the apparent potential for VR applications to be powerful to simulate exposure scenarios, there is no study of the comparison between active and passive exposure scenarios for social phobia.

Research has also shown the efficacy of active learning in comparison to passive learning from infants to adults. The active approach is more concerned with learning and experience, while the passive approach explains the perception by understanding of stimulus characteristics. According to a study on infants [26], a passive observation is not sufficient to change infants' behaviors. Based on adult learning theory, training adults can also be more successful when they are exposed to learning strategies that involve active practices [27]. The idea behind the active learning is the engagement of a learner in the learning process. Social phobia is a cognitive disorder that requires the engagement of a patient for treatment.

It is also shown that active distraction is more effective for patients undergoing painful procedures [28]. In comparison to passive scenarios, tasks that require patients to manipulate the environment utilize more attentional resources [29]. The process of interaction blocks additional modalities of sensory input, where this does not happen in passive distraction [30]. The exposure scenarios for phobia treatment are not effective when the patient is not engaged [31]. Active desensitization, in which the patient is asked to actively contact the source of fear, is an effective and rapid way to eliminate the fear [32].

\section{Related Work}

Various virtual reality applications to treat mental health problems have been proposed in recent years [33]. Research shows the efficacy of using VRET in comparison to waitlist control [34] [35]. In [36], healthy controls rated their fear higher during VR conversation than during in vivo conversation. It is also shown that VRET is more cost-effective method to treat social anxiety disorders $[37,38]$. The power of Second Life in behavior therapy to treat social anxiety disorders are studied in [9]. It is shown that this technique has a significant effect on improving social anxiety symptoms and depression. In [39], a virtual reality system is proposed to treat those suffering from social phobia. Instead of creating a 3D environment, the authors crated the sense of immersion using three-dimensional images without a need to use head mounted displays. Some research such as [19] has addressed the public speaking phobia as a specific type of social phobia. It is shown that VR public speaking scenarios can result in increasing heart rate, electrodermal activity, and self-reported distress.

In terms of creating a believable environment for VRET scenarios, various parameters such as increasing the sense of immersion and the sense of presence are taken into account [40]. These parameters have been reported for VR scenarios presented through HMDs. Research has shown that sophisticated simulations result in higher immersion and presence. As argued in [41], there are correlations between anxiety and presence. According to [42], different aspects of presence are associated with the experience of fear. In [43], it is shown that experienced presence in VRET scenarios are higher than the real world simulation. In [36], the lack of sync between an avatar's gestures and the voice has been considered as one of the main problems of VRET in terms of creating believable scenarios that engage users. They argue that providing facilities for a therapist 
to converse with the patient in real time in VRET scenarios makes it possible to create more a realistic space.

According to [44], VRET can result in behavior changes in real-life situations. Findings of [45] showed that younger patients who suffer from social phobia can better take advantages of VRET in comparison to older adults. In [33], the effect of VR using mobile applications to treat patients suffering from social phobia has been studied. In [1], social scenarios including conversion in a bus stop, a train station, and a clothing shop are used as VRET scenarios. As discussed in [1], the attitude of virtual character in a VRET scenario may affect the anxiety-level of people. Other scenarios such as bar, coffee shop scenario, dinner with neighbors, public transport and shoe store scenarios are already used in VRET scenarios [46]. In [47], in a public speaking phobia scenario, a patient has to deliver a speech or a presentation for virtual audience.

\section{VRET Applications}

In order to study and compare the effect of active and passive scenarios, we developed three active and passive virtual reality scenarios. In the following, the details of implementations as well as the specifications of these scenarios are explained.

\subsection{Specifications of the Scenarios}

Asking people to involve in boring scenarios can result in drop out from the whole therapy [8]. Designing therapy sessions as digital games can transform this unattractive process into intrinsically motivated action. The VRET scenarios proposed in this paper are implemented using attractive games, where the participants are exposed to social phobia in terms of game challenges. In these serious games, training, therapy, or behavioral change precedes the entertainment [48-54]. The virtual reality game developed for this study includes city, supermarket and metro scenarios, where each scenario is developed in both active and passive modes. In this game, players have to deal with people. This helps to encounter assertively with communication challenges and entertaining positive thoughts about themselves or their social environment. In order to achieve an optimal effectiveness, the exposure to a source of fear must be graduated [49]. In the city scenario, the game starts with a moderate social phobia condition in which the user has to move in a city full of people walking on the street. Later levels increase the challenge by requiring new interactive behaviors. In the supermarket scenario, the player must explore the store to find and pick up indicated items in order to complete the game. The player has to deal with other people in the supermarket and ask questions to find the items. They also need to interact with the seller to checkout the goods. Finally, in the metro scenario, the player must go to a destination indicated by the game. There is no map on the metro station, and the player has to ask several questions from passengers in the metro station to find her way. Screenshots of city, supermarket and metro scenarios are shown in Figure 1, Figure 2 and Figure 3, respectively.
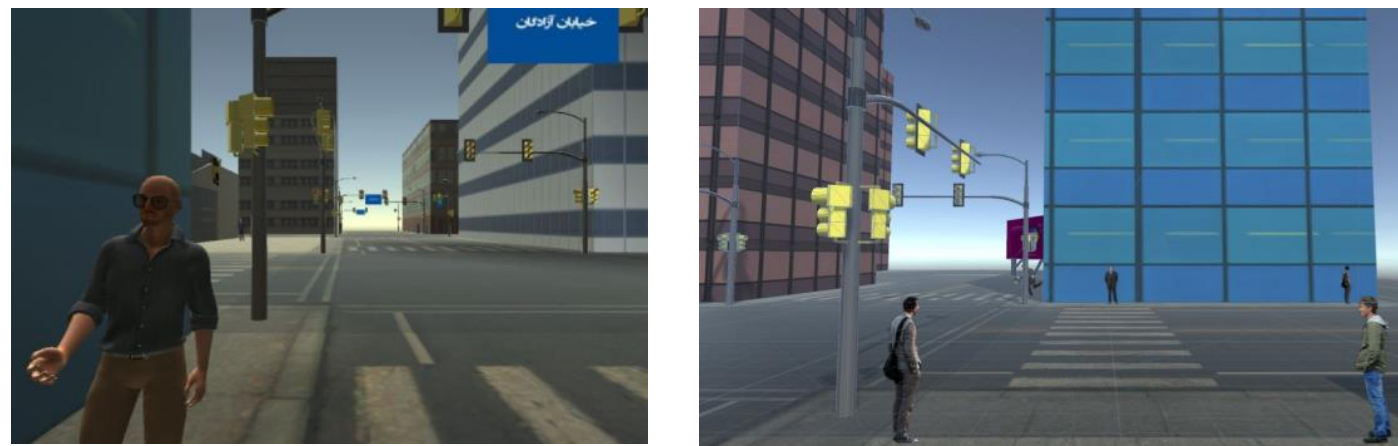

Figure 1. Screenshots of the city scenario, in which a player has to communicate with people in order to find her way to a predetermined location 

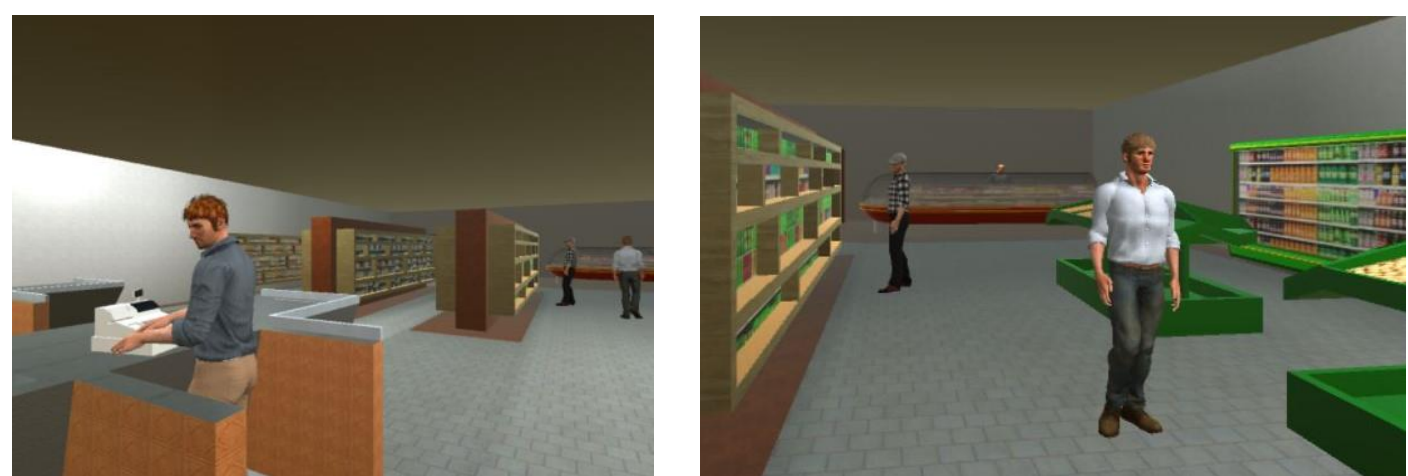

Figure 2. Screenshots of the supermarket scenario, in which a player has to ask customers where she can find a particular product.
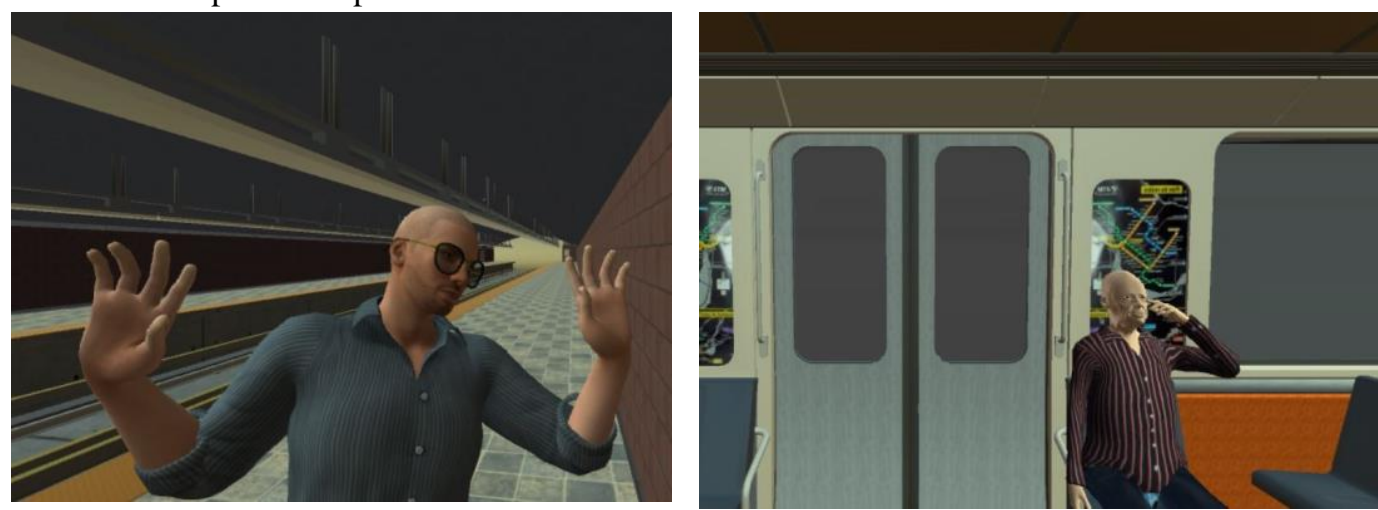

Figure 3. Screenshots of the metro scenario, in which a player has to communicate with passengers to find out which train she should take to a predetermined location.

\subsection{Active vs. Passive Scenarios}

Since the focus of this paper is to compare active and passive virtual reality exposure scenarios to elicit social anxiety, we need to carefully explain this concept. Active scenarios differ from the passive scenarios in that they require players to actively solve problems while playing the game. In these scenarios, the player needs to make quick decisions about which direction to move and how to avoid some other situations. For example, in the active city scenario, a player has a full control on the movements and behaviors of the character walking on the street. In this scenario, a player needs to stop in front of some random passengers in order to ask the address of a pre-defined destination. On the other hand, in the passive city scenario, the player has no control on the movements and the behaviors of the character. In this scenario, the camera automatically moves towards a pre-determined passenger on the street, where the player has to ask the address of the destination from this passenger. In this situation, the player cannot progress in the game without interaction with this passenger. Although in an active scenario a player still needs to ask an address to find her way, she can decide whom to ask or when to ask questions.

In the active supermarket scenario, a player can move between the racks, ask the employees where she can find items, and search for the items she wants to buy. On the other hand, in the passive supermarket scenario, the camera moves in the pre-determined path by the game. The camera stops in front of some selected employees where the player needs to ask where she can find some particular items. Accordingly, in the active metro scenario, this is the player who decides in which direction she must move or whom to ask about the trains. However, in the passive metro scenario, the player has to move in a pre-determined path and ask from passengers already defined by the scenarios of the game.

\subsection{Technical Specifications}

The prototypes of the games are android applications implemented in Unity game engine. In order to create a virtual reality environment, the mobile device is placed in VR Box head mounted display, which is an affordable virtual reality HMD similar to Google cardboard (Participants using this system in our experiments are shown in Figure 4). 
The non-player characters in the games are random people walking around the city. These characters are programmed to sense the world and take appropriate reactions based on a player's action in the game. Generally, in computer games based on artificial intelligence, the decision making process is programmed using the sense-think-act model, in which a non-player character uses different sensors to receive the status of world (sense), decides what to do based on this data (think), and performs some actions (action) [55]. In the game proposed in this paper, the RAIN component of Unity is used to develop sensors in the game that allows recognizing the player and non-player characters in the game space. Accordingly, the thinking section of the AI is developed using the behavior trees of RAIN as well as a Finite State Machine (FSM). Finally, the acting part including walking on the streets are developed using Navigation Mesh in Unity engine as well as waypoint module in RAIN. The overall architecture of the VR prototypes used in this paper is shown in Figure 5. Interaction with the game is provided through changing the position of the camera. For example, when the player looks up, the character moves in the forward direction. On the other hand, when the user looks down, the character stops. The source code of the prototypes is freely available to download at (removed for anonymity).
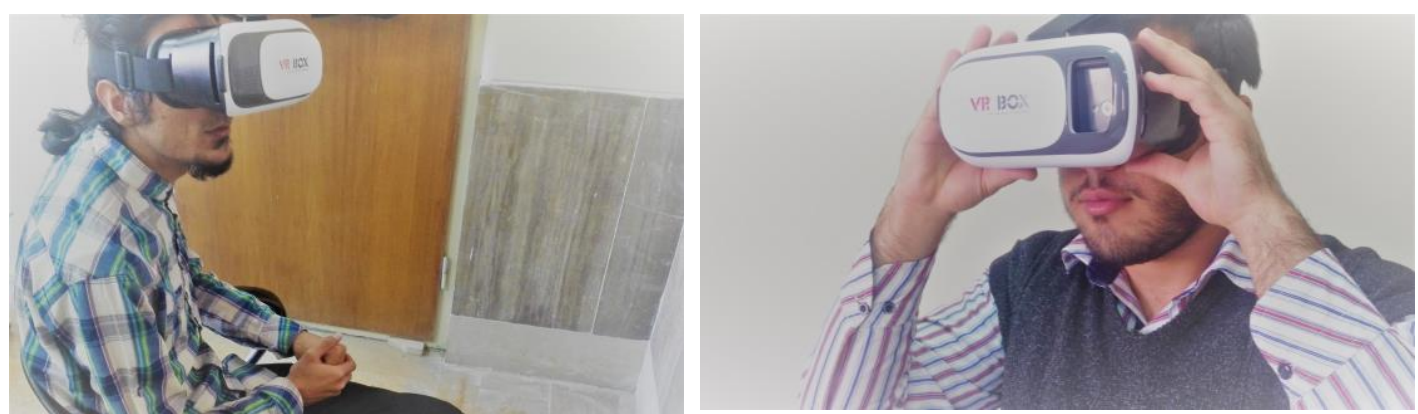

Figure 4. Participants using the VRET scenarios during the experiments

\section{4 Game Properties Eliciting Anxiety}

The VRET game proposed in this paper has some unique features that make this game different from simple social phobia simulations. The exposure scenarios are designed in terms of some attractive plans that persuades players to gain more rewards by passing through the crowds and communicating with them. Non-player characters in this game perform some distracting behaviors (e.g., sudden laugh or frequently looking around) to create more anxiety in the players who interact with them. Players gain more rewards communicating with these characters. All the communications are recorded in the game. This makes it possible for players to review the communications they had with the characters in the game. This feedback helps players to improve their communications in the future contacts.

In some extreme cases, non-player characters may approach the player to open a discussion or ask a question. These characters stay near the player until the player stops talking. The duration of time spent with these characters is mapped to particular rewards in the game that make it possible to progress in the game. During the game, a group of characters may stand near the player and speak about the player to create more anxiety. Players gain more rewards if they do not escape these situations. In the metro scenario, many Non-player characters may come close to the player in stand near the player when there is no enough space on the train. All of these techniques are used to elicit more anxiety in the player that support the desired treatment.

\section{Methods}

\subsection{Participants}

The total of 24 participants (fourteen females and ten males) from the students of (removed for anonymity) University were recruited for this study. The average age of the participants was 22.56 $(\mathrm{SD}=0.46)$. We did not perform a structured diagnostic interview. However, we used LSAS interviewer-rated questions [50] to assess the initial fear and avoidance of social situations. According to the mean value of 33.35 with $\mathrm{SD}=15.45$, we categorize participants as healthy participants in terms of social phobia. The experiments were conducted without any dropouts. 
Note that the population of participants for this research has been selected from healthy people. The rationale is that the focus of this paper is to show which of active or passive VRET scenarios can result in eliciting more social anxiety during exposure scenarios. Research has shown that VR exposure scenarios elicit psychological and physiological response patterns both in patients and healthy participants [47]. As discussed in [1], VRET scenarios can result in evoking anxiety in none-phobic participants. As discussed in [36], healthy participants can be used to measure if conversations with virtual avatars can result in increasing the feelings of social anxiety. Note that we do not claim the efficacy of using active scenarios to treat social phobia. Consequently, although the low LSAS mean indicates that most participants probably did not have the disorder, we focus on eliciting social anxiety and creating the sense of presence as two parameters reinforcing the efficacy of VRET to treat social anxiety disorders.

\subsection{Design}

The independent variable in this study is the type of virtual reality game that can include active scenarios (AS) or passive scenarios (PS). Since the environment, goal and the scenarios are almost the same in both AS and PS with a difference in the control of scenarios, in order to prevent the learning effect, we designed a between-subjects study, where the half of the participants $(n=12)$ used AS, and the other half $(n=12)$ used PS. Consequently, each participant was exposed only to one of the systems.

This paper aims to show that active VRET in which participants are actively engaging in the therapy session are more effective than passive scenarios. To this end, we examine and compare the ability of active and passive exposure scenarios in terms of eliciting subjective distress. We argue this is a construct valid measuring method to proof this idea because research has already shown that controlled increase in distress and anxiety of people in VRET scenarios results in the efficacy of using this technique to treat social anxiety disorders in long term. This makes sure the tests we use measures this claim.

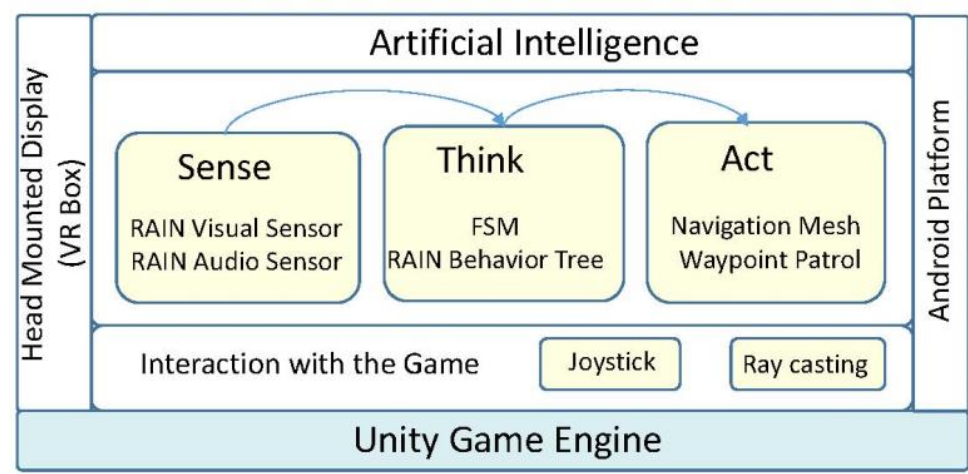

Figure 5. The overall architecture of the VR prototypes developed in this paper.

\subsection{Procedure}

The exposure process must be repeated and prolonged, and practice tasks should be clearly specified. Consequently, we designed a therapy including nine sessions (three sessions in a week, three weeks in a row). Each of three main scenarios (city, supermarket, and metro) was implemented at three difficulty levels including easy, intermediate and difficult levels. The number of people a player needs to interact with during the game, the type of conversation, and the length of scenarios are parameters indicating the difficulty of games. The first week starts with easy scenarios followed by the intermediate levels in the second week and finishes by the difficult scenarios in the third week. In the first introductory session, participants were asked to sign informed consent before starting the experiment. They were also asked to fill out a pre-study questionnaire regarding their background information.

\section{6. $\quad$ Results}

In this section, we report the results of various tests have been conducted to compare the effect of passive and active scenarios to elicit social anxiety and create the sense of presence and enjoyment in participants. 


\subsection{Social Anxiety}

The social anxiety index was measured in the beginning of the introductory sessions as well as at the end of each therapy session. A pair-wise Wilcoxon-Mann-Whitney test was conducted on this subjective data to identify if there were any statistically significant differences as a result of using passive (PS) and active (AS) scenarios for social phobia treatment using virtual reality exposure therapy. The rationale behind using this test is that there is no assumption of a specific distribution for the population. As shown in Table 1, the analysis found statistically significant differences between the anxiety levels in pre-test and post-test (after 3 weeks and 9 sessions of exposure for active and passive scenarios). In addition, the results show statistically significant differences between the post-test values of PS and AS. According to the results, the $Z$ value is less than -1:96 and p-value is less than 0.05. Consequently, there are statistically significant differences between social anxiety in AS and PS.

Table 1. Pair-wise comparison of the measure of confidence in the results social anxiety using Wilcoxon-Mann-Whitney tests.

\begin{tabular}{l|cc}
\hline Comparison of Data Sets & \multicolumn{2}{|c}{ Wilcoxon-Mann-Whitney Results } \\
\hline (PS pre-test) - (PS post-test) & $\mathrm{Z}=-2.061$, & $\mathrm{p}=0.0391$ \\
\hline (AS pre-test) - (AS post-test) & $\mathrm{Z}=-3.329$, & $\mathrm{p}=0.0009$ \\
\hline (PS post-test) - (AS post-test) & $\mathrm{Z}=-4.329$, & $\mathrm{p}=0.0007$ \\
\hline
\end{tabular}

\section{2 Presence, Enjoyment and SUD}

We used Multivariate analysis of variance (MANOVA) to determine the statistical impact each method (passive or active) have on dependent variables including presence, enjoyment and SUD. To measure social anxiety, we used Social Anxiety Questionnaire for Adults (SAQ-A30) [51]. This questionnaire includes series of social situations that may cause unease, stress or nervousness. Participants were asked to indicate their reaction in each situation, where "1" represents no unease, stress, or nervousness, and "5" represents very high or extreme unease, stress, or nervousness. The SUD scale is a measure of subjective anxiety $(0=$ no disturbance to $100=$ most disturbance $)$ reported by participants after using each system8. In order to measure presence, MECSPQ [52], which is a questionnaire to measure the sense of presence in virtual environments, was used. This questionnaire covers different aspects of presence including attention, involvement, spatial, and social presence. We asked participants to answer the questions that were rated on a 5-point Likert scale. The experience of enjoying the game was measured using 7-point rating scales including likeable, funny, interesting, exciting, challenging, and useful [56]. In each treatment session, participants were exposed to all city, metro and supermarket scenarios. However, different parameters including presence, enjoyment, SUD were analyzed separately.

Presence. The sense of presence is an important issue with regard to virtual reality environments [53]. Presence is defined as "the subjective expression of being in one place or environment, even one is physically situated in another" [54]. Different parameters can affect the sense of presence. What we measure in terms of the sense of presence for the VRET scenarios presented in this paper is the overall sense of presence by taking into account the application and the environmental parameters.

As shown in Table 2, the results indicate a significant effect of active scenarios to increase the presence levels of participants. In particular, the MANOVA test shows that subjects using active scenarios had significantly higher mean score of presence than subjects using passive scenarios. In particular, the results showed that participants rated active scenarios $(\mathrm{M}=4.33, \mathrm{SD}=1.01)$ significantly more than passive scenarios $(M=3.75, \mathrm{SD}=1.36)$. The independent analysis of different scenarios shows that there are also significant differences between active and passive scenarios for all scenarios (city scenario: $F=0.85$, supermarket scenario: $F=2.01$, metro scenario $1.12, \mathrm{p}<0.01)$. The results indicate that active scenarios can produce more presence than passive scenarios for the players. The original MECSPQ questionnaire is divided into four sections including involvement, interactivity, spatial presence and social presence as different aspects of presence. We analyzed the results of active and passive scenarios in terms of these four different aspects. The results showed that there are statistically significant differences between active and passive scenarios in terms of interactivity and social presence. However, there is no statistically significant difference between active and passive scenarios in terms of involvement, and spatial presence. 
Table 2. The results of multivariate analysis of variance on SUD, presence and Enjoyment

\begin{tabular}{|c|c|c|c|c|c|}
\hline & \multicolumn{2}{|c|}{$\begin{array}{c}\text { Passive } \\
\text { Scenarios }\end{array}$} & \multicolumn{2}{|c|}{$\begin{array}{c}\text { Active } \\
\text { Scenarios }\end{array}$} & \multirow[t]{2}{*}{$\mathrm{F}$} \\
\hline & M & $\mathrm{SD}$ & M & SD & \\
\hline Presence & 3.75 & 1.36 & 4.33 & 1.01 & $15.12 * *$ \\
\hline City & 2.95 & 0.95 & 3.98 & 1.09 & $19.47 * *$ \\
\hline Supermarket & 3.21 & 1.26 & 4.06 & 0.85 & $16.19 * *$ \\
\hline Metro & 3.09 & 1.30 & 4.36 & 0.96 & $23.22 * *$ \\
\hline Enjoyment & 4.58 & 0.98 & 4.95 & 0.75 & 1.13 \\
\hline City & 4.26 & 1.25 & 4.76 & 0.95 & 0.85 \\
\hline Supermarket & 4.33 & 0.88 & 5.13 & 0.96 & 2.01 \\
\hline Metro & 4.48 & 0.53 & 4.93 & 0.75 & 1.12 \\
\hline SUD & 49.61 & 15.85 & 59.52 & 9.73 & $13.86^{* *}$ \\
\hline City & 48.26 & 14.25 & 69.36 & 10.58 & $26.33 * *$ \\
\hline Supermarket & 45.12 & 11.05 & 58.35 & 15.65 & $23.25 * *$ \\
\hline Metro & 59.33 & 12.66 & 71.02 & 11.26 & $16.08 * *$ \\
\hline
\end{tabular}

$* * \mathrm{p}<0.01$

Enjoyment. Descriptive statistics for the experience of the game as a whole and for separate levels for AS and PS can be found in Table 2. As shown in this table, there is no statistically significant differences between active and passive scenarios in terms of enjoyment for all scenarios. This rejects our hypothesis that active scenarios can result in more enjoyment for the players than passive sceanrios.

SUD. We were also interested to measure the subjective unit of disturbance (SUD) during the experiments in long-term. To this end, participants were asked to rate their subjective anxiety by a number between 0 and 100 after performing each scenario. Only one number is recorded for each performing of scenarios that relates to the highest level that their SUDs reached. As shown in Table 2, there is statistical significance in the differences $(\mathrm{F}=13.86)$ between the SUD values of active scenarios $(M=59.52, S D=9.73)$ and passive scenarios $(M=49.61, S D=15.85)$. As a result, we conclude that the hypothesis that active scenarios can result in more anxiety is supported. We were also interested to find the trends of anxiety level for PS and AS during for whole therapy process. The distribution of SUD values for participants of passive and active scenarios are shown in box plots in Figure 6.

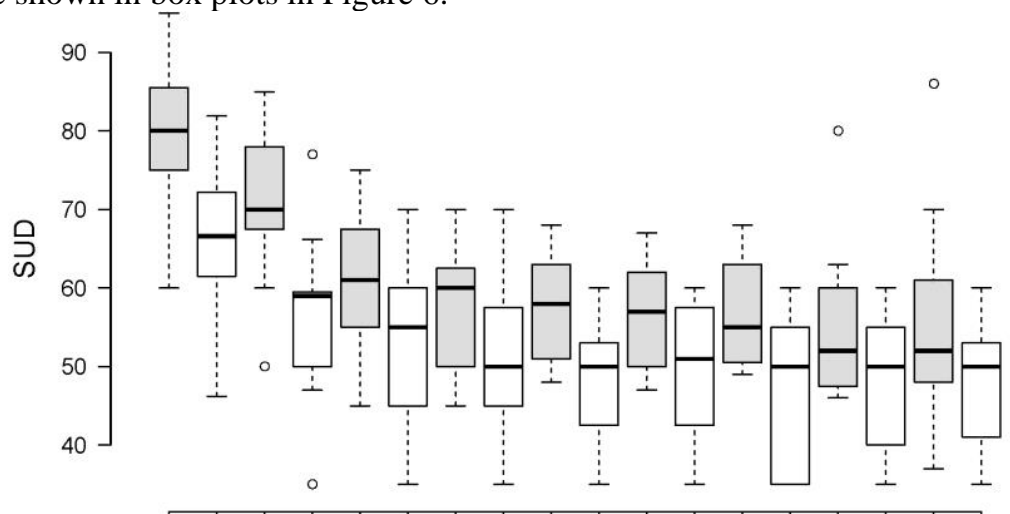

1А 1P 2A 2P 3А 3Р 4A 4P 5A 5P 6A 6'P 7A 7P 8'A 8'P 9'A 9P

session\#scenario ( $P$ for passive and $A$ for Active)

Figure 6. The distribution of SUD values each passive and active therapy sessions

Correlation analysis. We performed Pearson correlation analysis to measure the strengths of association between presence and SUD. In terms of the strength of relationship, according to $r=0.897$ for participants using passive scenarios (Figure $7(\mathrm{a})$ ), and $\mathrm{r}=0.952$ for participants using passive scenarios (Figure 7(b)), there is a high degree of association between presence and SUD. 
(a) Passive scenarios

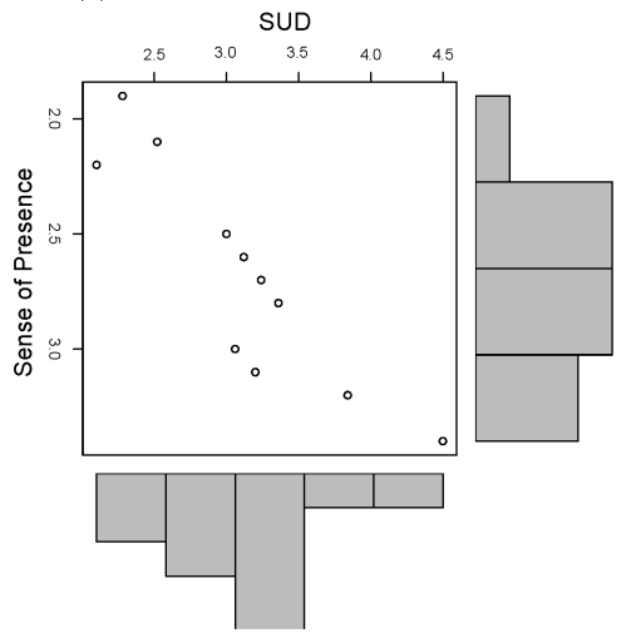

(b) Active scenarios

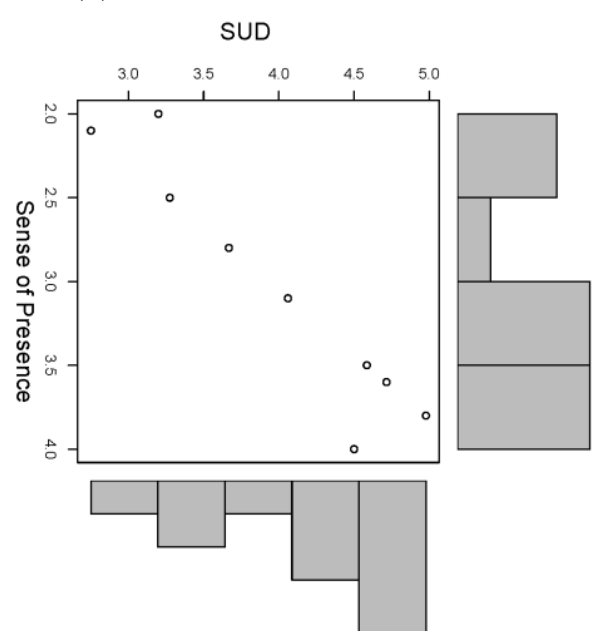

Figure 7. Correlation between SUD and the sense of presence in the experiments

\section{Discussion}

This pilot study aimed to test whether virtual reality exposure therapies with active scenarios are more effective than passive scenarios to elicit social anxiety. As predicted based on theoretical findings regarding active engagement in the treatment procedure, VRET with active scenarios (AS) showed a higher decrease of social anxiety than the VRET with passive scenarios (PS). The results showed that both active and passive scenarios are effective to reduce social anxiety disorders. However, it was concluded that the hypothesis of "active social phobia exposure scenarios are more effective than passive exposure scenarios in terms of reducing the social anxiety level" is supported.

As also expected, the AS condition outperformed the PS condition on the presence measures. As expected, involvement and spatial presence were not affected by the parameter of passive or active scenarios. between the user and the virtual environment. However, social presence, which is known as ("the sense of being together with another.") as well as interaction parameters were directly affected by the interaction techniques used in active and passive scenarios.

Participants rated their subjective anxiety for the AS condition higher than the PS condition, concluding that active scenarios can result in more anxiety and as a result, a better exposure to social phobia conditions. This indicates that the active engagement of people in exposure scenarios results in more anxiety and consequently, a stronger exposure scenario. The results also showed that participants had a higher level of anxiety in the first week of the therapy sessions, while the anxiety level was reduced considerably one session after another. One possible explanation is that participants were adapted to VR scenarios very soon. These findings imply that in order to make gradual changes in the anxiety level of participants, passive scenarios can be used in the first few therapy sessions, while active scenarios can be used in the later sessions.

The analyses of enjoyment did not reveal a difference between AS and PS conditions. One possible explanation is that although active scenarios are more challenging and should result in more fun and enjoyment based on the theory of fun in computer games, since players are more comfortable to play the passive scenarios, this may have resulted in reducing the enjoyment. We argue in order to increase the enjoyment of the game, other factors such as creating multiple goals in the game and balancing between the skills of a player and the challenges of the game should be taken into account in the design of VRET games.

One of the main features of the technique we propose is the ability of performing the exposure sessions at the users' place without the direct intervention of therapist, where the rest of the sessions can be held at the users place with an online sending of the usage report directly to the therapist. However, in this study, in order to control the environment and make sure all participants go through the same procedure, all exposure sessions were held at (removed for anonymity).

Since all active and passive scenarios proposed in this paper are applied using head mounted displays, technology imposed anxiety for both scenarios are the same. In order to alleviate the effect of technology imposed anxiety, all participants were recruited from the students of 
Multimedia department, where they all had an experience of working with and implementing VR scenarios in practice. Moreover, participants were asked to use some sample fun scenarios (other than the scenarios were used in the main experiments) to become familiar with the VR technology. However, it is possible that part of the anxiety measured during the experiments may have been due to technology anxiety.

\section{Conclusion and Future work}

In this paper, we studied and compared the effect of active and passive virtual reality scenarios to elicit social anxiety. With the advent of virtual reality as a clinical tool, it will grow increasingly important to identify factors that might mitigate or enhance the effectiveness of these technologies. We compared active and passive anxiety eliciting scenarios in an experimental study. According to the results of experiments, although both active and passive scenarios are effective to elicit social anxiety, active social phobia exposure scenarios are more effective than passive exposure scenarios in terms of eliciting anxiety and consequently, creating stronger exposure scenarios. We argue this difference is because of using anxiety eliciting techniques in the active game scenarios. In terms of enjoyment, our study did not find statistically significant differences between the enjoyment of participants using active and passive scenarios.

This study suffers from some limitations that we aim to address in future work. First, as the current study focused on differences between passive and active scenarios in eliciting social anxiety, we tested healthy participants. In the future work, we will study the effectiveness of different anxiety eliciting techniques employed in this paper. We also aim to determine the effect of these scenarios on patients with high social anxiety. Although SUDs and self-reported questioners are often used to measure the level of anxiety and fear, we aim to incorporate physiological measures such as heart rate, blood pressure and skin conductance to better measure distress and anxiety.

\section{Acknowledgment}

We would like to thank the editor and all anonymous reviewers of this paper from International Journal of Serious Games to provide constructive comments for improving the quality of this paper.

\section{References}

[1] Brinkman, W. P., Van der Mast, C. A. P. G., de Vliegher, D. Virtual reality exposure therapy for social phobia: A pilot study in evoking fear in a virtual world. Delft University of Technology 2008; 1:85-88.

[2] Borkovec, T. D., Costello, E. Efficacy of applied relaxation and cognitive-behavioral therapy in the treatment of generalized anxiety disorder. Journal of consulting and clinical psychology 1993; 61(4):611. https://doi.org/10.1037/0022-006X.61.4.611

[3] Casale, M. B., Mittal, A., Whalen, C., Stahmer, A., Quiocho, J., \& Vejnoska, S. F. (2015). One Size Does Not Fit All: A Smarter Way to Develop Computer Assisted Interventions for Children with ASD. The International Journal of Serious Games, 2(2). https://doi.org/10.17083/ijsg.v2i2.63

[4] Dalrymple, K. L., Herbert, J. D. Acceptance and commitment therapy for generalized social anxiety disorder a pilot study. Behavior Modification 2007; 31(5): 543-568. https://doi.org/10.17083/ijsg.v2i2.63

[5] Gega, L., White, R., Clarke, T., Turner, R., Fowler, D. Virtual environments using video capture for social phobia with psychosis. Cyberpsychology, Behavior, and Social Networking 2013; 16(6): 473-479. https://doi.org/10.1089/cyber.2013.1510

[6] Sohn, B. K., Hwang, J. Y., Park, S. M., Choi, J. S., Lee, J. Y., Lee, J. Y., Jung, H. Y. Developing a Virtual Reality-Based Vocational Rehabilitation Training Program for Patients with Schizophrenia. Cyberpsychology, Behavior, and Social Networking 2016; 19(11): 686691. https://doi.org/10.1089/cyber.2016.0215 
[7] Pallavicini, F., Serino, S., Cipresso, P., Pedroli, E., Chicchi Giglioli, I. A., Chirico, A., Riva, G. Testing augmented reality for cue exposure in obese patients: an exploratory study. Cyberpsychology, Behavior, and Social Networking, 2016; 19(2): 107-114. https://doi.org/10.1089/cyber.2015.0235

[8] Zielhorst, T., van den Brule, D., Visch, V., Melles, M., van Tienhoven, S., Sinkba ek, H., Lange, A. Using a Digital Game for Training Desirable Behavior in Cognitive-Behavioral Therapy of Burnout Syndrome: A Controlled Study. Cyberpsychology, Behavior, and Social Networking 2015; 18(2): 101-111. https://doi.org/10.1089/cyber.2013.0690

[9] Yuen, E. K., Herbert, J. D., Forman, E. M., Goetter, E. M., Comer, R., Bradley, J. C. Treatment of social anxiety disorder using online virtual environments in second life. Behavior Therapy 2013; 44(1): 51-61. https://doi.org/10.1016/j.beth.2012.06.001

[10] Craske, M. G., Kircanski, K., Zelikowsky, M., Mystkowski, J., Chowdhury, N., Baker, A. Optimizing inhibitory learning during exposure therapy. Behaviour research and therapy 2008; 46(1): 5-27. https://doi.org/10.1016/j.brat.2007.10.003

[11] Krijn, M., Emmelkamp, P. M., Olafsson, R. P., Biemond, R. Virtual reality exposure therapy of anxiety disorders: A review. Clinical psychology review 2004; 24(3): 259-281. https://doi.org/10.1016/j.cpr.2004.04.001

[12] Taylor-Nelms, L., \& Hill, V. Assessing 3D Virtual World Disaster Training Through Adult Learning Theory. The International Journal of Serious Games, 2014; 1(4): 3-16. https://doi.org/10.17083/ijsg.v1i4.40

[13] Imbellone, A., Botte, B., \& Medaglia, C. M. Serious games for mobile devices: the intouch project case study. International Journal of Serious Games, 2015; 2(1): 17-27. https://doi.org/10.17083/ijsg.v2i1.41

[14] Van der Kooij, K., Hoogendoorn, E., Spijkerman, R., \& Vish, V. Validation of games for behavioral change: connecting the playful and serious. International Journal of Serious Games, 2015; 2: 63-75. https://doi.org/10.17083/ijsg.v2i3.75

[15] Andersson, G. Using the Internet to provide cognitive behaviour therapy. Behaviour research and therapy 2009; 47(3): 175-180. https://doi.org/10.1016/j.brat.2009.01.010

[16] Berger, T., Hohl, E., Caspar, F. Internet-based treatment for social phobia: a randomized controlled trial. Journal of clinical psychology 2009; 65(10): 1021-1035. https://doi.org/10.1002/jclp.20603

[17] Titov, N., Andrews, G., Johnston, L., Schwencke, G., Choi, I. Shyness programme: longer term benefits, cost-effectiveness, and acceptability. Australian and New Zealand Journal of Psychiatry 2009; 43(1): 36-44. https://doi.org/10.1080/00048670802534424

[18] Garcia-Palacios, A., Botella, C., Hoffman, H., Fabregat, S. Comparing acceptance and refusal rates of virtual reality exposure vs. in vivo exposure by patients with specific $\begin{array}{lllll}\text { phobias. Cyberpsychology } \quad \& \quad \text { behavior } & 2007 ; 10(5): & 722-724 \text {. }\end{array}$ https://doi.org/10.1089/cpb.2007.9962

[19] Owens, M. E., Beidel, D. C. Can Virtual Reality Effectively Elicit Distress Associated with Social Anxiety Disorder?. Journal of Psychopathology and Behavioral Assessment 2015; 37(2): 296-305. https://doi.org/10.1007/s10862-014-9454-X

[20] Hartanto, D., Kampmann, I. L., Morina, N., Emmelkamp, P. G., Neerincx, M. A., Brinkman, W. P. Controlling social stress in virtual reality environments. PloS one 2014; 9(3): e92804. https://doi.org/10.1371/journal.pone.0092804

[21] Sekhavat, Y. A. KioskAR: An Augmented Reality Game as a New Business Model to Present Artworks. International Journal of Computer Games Technology, 2016; (2016): 1-12. DOI: $10.1155 / 2016 / 7690754$

[22] Sekhavat, Y. A. Nowcasting Mobile Games Ranking Using Web Search Query Data. International Journal of Computer Games Technology, 2016; (2016):1-9. DOI: $10.1155 / 2016 / 9859813$

[23] Nash, E. B., Edwards, G. W., Thompson, J. A., Barfield, W. A review of presence and performance in virtual environments. International Journal of human-computer Interaction 2000; 12(1): 1-41. https://doi.org/10.1207/S15327590IJHC1201_1

[24] Schubert, T., Friedmann, F., Regenbrecht, H. The experience of presence: Factor analytic insights. Presence 2001; 10(3): 266-281. https://doi.org/10.1162/105474601300343603

[25] Sekhavat, Y. A. Privacy Preserving Cloth Try-On Using Mobile Augmented Reality. IEEE Transactions on Multimedia, 19(5): 1041-1049 https://doi.org/10.1109/TMM.2016.2639380

[26] Libertus, K., Needham, A. Teach to reach: The effects of active vs. passive reaching experiences on action and perception. Vision research 2010; 50(24): 2750-2757. https://doi.org/10.1016/j.visres.2010.09.001 
[27] Romoser, M. R., Fisher, D. L. The effect of active versus passive training strategies on improving older drivers' scanning in intersections. Human Factors: The Journal of the Human $\begin{array}{lllll}\text { Factors and } & \text { Ergonomics }\end{array}$ https://doi.org/10.1177/0018720809352654

[28] Dahlquist, L. M. Commentary on" Treatments that work in pediatric psychology: Procedurerelated pain."

[29] Haythornthwaite, J. A., Lawrence, J. W., Fauerbach, J. A. Brief cognitive interventions for burn pain. Annals of Behavioral Medicine 2001; 23(1): 42-49. https://doi.org/10.1207/S15324796ABM2301_7

[30] Dahlquist, L. M., McKenna, K. D., Jones, K. K., Dillinger, L., Weiss, K. E., Ackerman, C. S. Active and passive distraction using a head-mounted display helmet: effects on cold pressor pain in children. Health Psychology 2007; 26(6): 794. https://doi.org/10.1037/02786133.26.6.794

[31] De Silva, P., Rachman, S. Is exposure a necessary condition for fear-reduction?. Behaviour Research and Therapy 1981; 19(3), 227-232. https://doi.org/10.1016/0005-7967(81)90006-1

[32] Murphy, C. M. Active and passive participation in the contact desensitization of snake fear in children. Behavior Therapy 1973; 4(2): 203-211. https://doi.org/10.1016/S00057894(73)80029-2

[33] Repetto, C., Gaggioli, A., Pallavicini, F., Cipresso, P., Raspelli, S., \& Riva, G. Virtual reality and mobile phones in the treatment of generalized anxiety disorders: a phase-2 clinical trial. Personal and Ubiquitous Computing, 2013; 17(2): 253-260. https://doi.org/10.1007/s00779011-0467-0

[34] McCann, R. A., Armstrong, C. M., Skopp, N. A., Edwards-Stewart, A., Smolenski, D. J., June, J. D., .. \& Reger, G. M. (2014). Virtual reality exposure therapy for the treatment of anxiety disorders: an evaluation of research quality. Journal of anxiety disorders, 2014; 28(6): 625631. https://doi.org/10.1016/j.janxdis.2014.05.010

[35] Anderson, P. L., Price, M., Edwards, S. M., Obasaju, M. A., Schmertz, S. K., Zimand, E., \& Calamaras, M. R. Virtual reality exposure therapy for social anxiety disorder: a randomized controlled trial. Journal of consulting and clinical psychology, 2013; 81(5): 751. https://doi.org/10.1037/a0033559

[36] Powers, M. B., Briceno, N. F., Gresham, R., Jouriles, E. N., Emmelkamp, P. M., \& Smits, J. A. Do conversations with virtual avatars increase feelings of social anxiety?. Journal of anxiety disorders, 2013; 27(4): 398-403. https://doi.org/10.1016/j.janxdis.2013.03.003

[37] Opriş, D., Pintea, S., García-Palacios, A., Botella, C., Szamosközi, Ş., \& David, D. Virtual reality exposure therapy in anxiety disorders: a quantitative meta-analysis. Depression and anxiety, 2012; 29(2): 85-93. https://doi.org/10.1002/da.20910

[38] Malbos, E., Rapee, R. M., \& Kavakli, M. A controlled study of agoraphobia and the independent effect of virtual reality exposure therapy. Australian and New Zealand Journal of Psychiatry, 2012.

[39] Gebara, C. M., Barros-Neto, T. P. D., Gertsenchtein, L., \& Lotufo-Neto, F. Virtual reality exposure using three-dimensional images for the treatment of social phobia. Revista Brasileira de Psiquiatria, 2016; 38(1): 24-29. https://doi.org/10.1590/1516-4446-2014-1560

[40] Diemer, J., Alpers, G. W., Peperkorn, H. M., Shiban, Y., \& Mühlberger, A. The impact of perception and presence on emotional reactions: a review of research in virtual reality. Frontiers in psychology, 2015; 6: 26. https://doi.org/10.3389/fpsyg.2015.00026

[41]Ling, Y., Nefs, H. T., Morina, N., Heynderickx, I., \& Brinkman, W. P. A meta-analysis on the relationship between self-reported presence and anxiety in virtual reality exposure therapy for anxiety disorders. PloS one, 2014; 9(5): e96144. https://doi.org/10.1371/journal.pone.0096144

[42] Price, M., Mehta, N., Tone, E. B., \& Anderson, P. L. Does engagement with exposure yield better outcomes? Components of presence as a predictor of treatment response for virtual reality exposure therapy for social phobia. Journal of anxiety disorders, 2011; 25(6): 763-770. https://doi.org/10.1016/j.janxdis.2011.03.004

[43] Villani, D., Repetto, C., Cipresso, P., \& Riva, G. May I experience more presence in doing the same thing in virtual reality than in reality? An answer from a simulated job interview. $\begin{array}{llll}\text { Interacting with } & \text { Computers, } & 2012 ; & 265-272 \text {. }\end{array}$ https://doi.org/10.1016/j.intcom.2012.04.008

[44] Morina, N., Ijntema, H., Meyerbröker, K., \& Emmelkamp, P. M. Can virtual reality exposure therapy gains be generalized to real-life? A meta-analysis of studies applying behavioral assessments. Behaviour research and therapy, 2015; 74: 18-24. https://doi.org/10.1016/j.brat.2015.08.010 
[45] Grenier, S., Forget, H., Bouchard, S., Isere, S., Belleville, S., Potvin, O., ... \& Talbot, M. Using virtual reality to improve the efficacy of cognitive-behavioral therapy (CBT) in the treatment of late-life anxiety: preliminary recommendations for future research. International Psychogeriatrics, 2015 27(07): 1217-1225. https://doi.org/10.1017/S1041610214002300

[46] Klinger, E., Légeron, P., Roy, S., Chemin, I., Lauer, F., \& Nugues, P. Virtual reality exposure in the treatment of social phobia. Studies in health technology and informatics, 2003; 99: 91119.

[47] Cláudio, A. P., Carmo, M. B., Pinheiro, T., Esteves, F., \& Lopes, E.Virtual environment to treat social anxiety. In International Conference of Design, User Experience, and Usability 2013; 442-451. https://doi.org/10.1007/978-3-642-39241-2_49

[48] Lee, Y. H., Heeter, C., Magerko, B., Medler, B. Gaming mindsets: Implicit theories in serious game learning. Cyberpsychology, behavior, and social networking 2012; 15(4): 190-194. https://doi.org/10.1089/cyber.2011.0328

[49] Roungas, B. A Model-Driven Framework for Educational Game Design. The International Journal of Serious Games, 2016; 3(3): 19-37. https://doi.org/10.17083/ijsg.v3i3.126

[50]Liebowitz MR. Social phobia. Mod Probl Pharmacopsychiatry 1987; 22:141-173. https://doi.org/10.1159/000414022

[51] Caballo, V. E., Salazar, I. C., Irurtia, M. J., Arias, B., and CISO-A Research Team. (2012). Social Anxiety Questionnaire for Adults (SAQ-A30). Measurement Instrument Database for the Social Science.

[52] Vorderer, P., Wirth, W., Gouveia, F. R., Biocca, F., Saari, T., Jäncke, F., Klimmt, C. (2004). MEC spatial presence questionnaire (MEC-SPQ): Short documentation and instructions for application. Report to the European Community, Project Presence: MEC (IST-2001-37661), 3.

[53]Loomis, J. M. Presence in Virtual Reality and Everyday Life: Immersion within a World of Representation. PRESENCE: Teleoperators and Virtual Environments, 2016; 25(2): 169-174. https://doi.org/10.1162/PRES_a_00255

[54] Van der Kooij, K., Hoogendoorn, E., Spijkerman, R., \& Visch, V. T. (2015). Validation of serious games. International Journal of Serious Games, 2 (3), 53-65. https://doi.org/10.17083/ijsg.v2i3.75

[55] Sekhavat Y.A., Behavior Trees for Computer Games, International Journal of Artificial $\begin{array}{lllll}\text { Intelligence } & \text { Tools, } & 2017 ; & 26(2): & 1730001-\end{array}$ https://doi.org/10.1142/S0218213017300010 